\title{
Free Vibration Analysis of a Cross-Ply Laminated Plate in Thermal Environment
}

\author{
Yusuf Ziya YÜKSEL ${ }^{a^{*}}$ and Şeref Doğuşcan AKBAŞ ${ }^{b}$ \\ ${ }^{a, b}$ Bursa Technical University, Department of Civil Engineering, Bursa, Turkey. \\ E-mail address: yusuf.yuksel@btu.edu.tr ${ }^{{ }^{*}}{ }^{*}$ seref.akbas@ @tu.edu.tr ${ }^{\mathrm{b}}$
}

Received date: 03.09.2018

Accepted date: 30.10 .2018

ORCID numbers of authors

$0000-0002-2615-1590^{\mathrm{a}}, 0000-0001-5327-3406^{\mathrm{b}}$

\begin{abstract}
This paper presents free vibration analysis of a cross-ply laminated plate under temperature rising with considering temperature-dependent physically properties. Material properties of laminas are orthotropic and temperature-dependent. In the kinematic model of the plate, first-order shear deformation plate theory is used. In solution method, the Navier procedure is used for a simply supported plate. The vibration frequencies of the laminated plate are obtained and discussed for different values of temperature, sequence of laminas and orientation angle of layers. Also, the difference between temperature dependent and independent physical properties is investigated.
\end{abstract}

Keywords: Composite Materials; Laminated Plates; Free Vibration; Temperature Rising.

\section{Introduction}

Laminated composite structures have been used a lot of engineering applications, for example; aircrafts, space vehicles, automotive engineering, defence industries and civil engineering applications because these structures have higher strength-weight ratios, more lightweight and ductile properties than classical materials. In generally, laminated composite structures are used in higher thermal systems. Hence, the temperature effect is very important issue of laminated composite structures and their design. In the literature, studies about temperature problems in composite plates are; Pal [1] analyzed nonlinear vibrations of plates under thermal loading. Chen and Chen [2] examined thermal buckling of laminated plates by finite element method. Chen and Chen [3] studied thermal post-buckling of laminated plates under thermal loading. Liu and Huang [4] analyzed vibration of laminated plates under thermal loading with first shear deformation plate theory (FSDPT). F. Lee et al. [5] studied free vibration of symmetrically laminated plates with FSDPT. Reddy and Chin [6] investigated dynamic thermo-elastic analysis of functionally graded cylinders and plates. Lee and Saravanos [7] studied thermo-piezoelectric composite materials with thermal effects with temperature dependent material properties. Reddy [8] performed static analysis of functionally graded plates by using FSDPT. Jane and Hong [9] investigated thermal problems of thin laminated rectangular orthotropic plates by 
using generalized differential quadrature method. Shen [10] examined thermal post-buckling of laminated plate resting on elastic foundation. Singha et al. [11] studied thermal postbuckling of graphite/epoxy laminated plates of various by finite element method. Sayman [12] analyzed elastic-plastic behavior of aluminum metal-matrix laminated plate under temperature effect. Patel et al. [13] examined flexural analysis of laminated plates of bimodulus materials under temperature effect. Shukla et al. [14] investigated postbuckling of laminated plates under temperature effect. Liew et al. [15] examined thermal buckling/post-buckling of thick laminated plates uniform temperature rising. Emery et al. [16] investigated thermoelastic stress analysis of laminated orthotropic plates. Shen [17] examined nonlinear analysis of functionally graded nanocomposite plates reinforced by single-walled carbon nanotubes under temperature effect. Zenkour and Alghamdi [18] examined bending of functional graded layered plates under thermal and mechanical loads. Vosoughi et al. [19] examined thermal postbuckling thermal postbuckling behavior of laminated composite skew with temperature dependent material properties. Kishore et al. [20] investigated nonlinear analysis of magnetostrictive layered plate by using third order shear deformation theory. Sahoo and Singh [21] presented static analysis of layered plates by using the hyperbolic zigzag theory. Carrera et al. [22] analyzed static stress problems in multi-layer plates. Sahoo and Singh [23] examined static analysis of layered plates by using a new inverse trigonometric ZigZag theory. Chen et al. [24] investigated thermal buckling and vibration of composite plates with temperature-dependent material properties and initially stressed. Torabizadeh and Fereidoon [25] solved general laminated composite plates under mechanical and thermal loading. Houmat [26] investigated the geometrically nonlinear free vibration of laminated composite rectangular plates with curvilinear fibers. Khorshid and Farhadi [27] investigated hydrostatic vibration analysis of a laminated composite rectangular plate partially contacting with a bounded fluid. Akbaş [28,29,30,31,32,33,34,35,36,37,38] investigated dynamics and stability of functionally graded composite beams by using finite element method. Sayyad et al. [39,40] solved thermoelastic analysis of laminated plates under thermal loading. Li and Qiao [41,42] examined thermal postbuckling analysis of laminated composite beams under thermal loading. Akbaş [43] examined a nano-plate by using generalized differential quadrature method. Ramos et al. [44] investigated thermoelastic static analysis of composite plates by using a new combined trigonometric equation. Akbaş [45,46] investigated functionally graded porous plates. Choudhury et al. [47] solved stress analysis of composite plate under thermo mechanical loads. Akbaş $[48,49,50]$ investigated thee laminated beams with nonlinear behavior. Akbaş [51] examined bi-material composite beams by using finite element method. Yüksel et al. [52] examined temperature dependent vibration of a simply supported plate by using the Navier method. Yüksel and Akbaş [53] investigated the stress analysis of a laminated composite plate under temperature rising. Also, many researchers investigated vibration, buckling, post-buckling analysis of nano composites, functionally graded composite structures in thermal and mechanical loads [54-73].

In this paper, free vibration of cross-play laminated plate examined under thermal effects. In constitute model of laminas, orthotropic and temperature-dependent properties are used. FSDPT is used in plate model. The Navier procedure is used for a simply supported plate. Effects of temperature, sequence of laminas and orientation angle of layers on the vibration characterises of laminated plate are investigated in temperature-dependent physically property. 


\section{Theory and Formulations}

In figure 1, a simply supported rectangular cross-ply laminated composite plate with thickness $h$, the length of $L_{X_{1}}$ and $L_{X_{2}}$ is displayed. Laminated composite plate is subjected to a nonuniform temperature rising with temperature rising values at the bottom surface $\Delta T_{B}$ and top surface $\Delta T_{T}$. Height of face sheet layers is equal to each other. In this study, numbers of the laminas are selected as two and three.

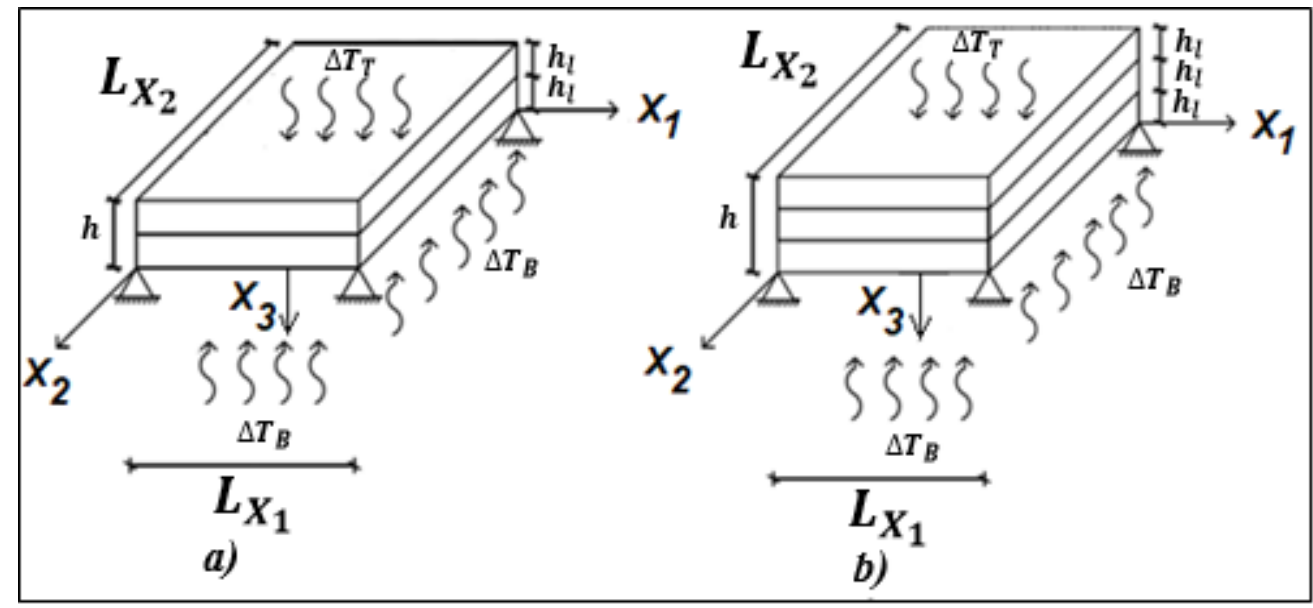

Fig. 1. A simply supported laminated rectangular composite plate under non-uniform temperature rising for a) two layer and b) three layer.

Based on FSDPT, the strain-displacement relations are expressed as;

$$
\begin{aligned}
& \varepsilon_{X_{1} X_{1}}=\frac{\partial u_{01}}{\partial X_{1}}+X_{3} \frac{\partial \emptyset_{X_{1}}}{\partial X_{1}} \quad \varepsilon_{X_{2} X_{2}}=\frac{\partial u_{02}}{\partial X_{2}}+X_{3} \frac{\partial \emptyset_{X_{2}}}{\partial X_{2}} \\
& \gamma_{X_{1} X_{2}}=\frac{\partial u_{02}}{\partial X_{2}}+\frac{\partial u_{02}}{\partial X_{1}}+X_{3}\left(\frac{\partial \emptyset_{X_{1}}}{\partial X_{2}}+\frac{\partial \emptyset_{X_{2}}}{\partial X_{1}}\right) \\
& \gamma_{X_{1} X_{3}}=\frac{\partial u_{03}}{\partial X_{1}}+\emptyset_{X_{1}}, \gamma_{X_{2} X_{3}}=\frac{\partial u_{03}}{\partial X_{2}}+\emptyset_{X_{2}}, \varepsilon_{X_{3} X_{3}}=0
\end{aligned}
$$

where $u_{01}, u_{02}, u_{03}$ indicate displacements in $X_{1}, X_{2}$ and $X_{3}$ directions, respectively. Constitutive expressions of orthotropic laminated plate for $n$th layer with temperature effect are given as follows:

$$
\begin{aligned}
& \left\{\begin{array}{l}
\sigma_{X_{1} X_{1}} \\
\sigma_{X_{2} X_{2}} \\
\sigma_{X_{1} X_{2}}
\end{array}\right\}^{(n)}=\left[\begin{array}{lll}
\bar{Q}_{11}(T) & \bar{Q}_{12}(T) & \bar{Q}_{16}(T) \\
\bar{Q}_{12}(T) & \bar{Q}_{22}(T) & \bar{Q}_{26}(T) \\
\bar{Q}_{16}(T) & \bar{Q}_{26}(T) & \bar{Q}_{66}(T)
\end{array}\right]^{(n)}\left\{\begin{array}{c}
\frac{\partial u_{01}}{\partial X_{1}}-X_{3} \frac{\partial^{2} u_{03}}{\partial X_{1}{ }^{2}}-\bar{\alpha}_{11}(T) \Delta T \\
\frac{\partial u_{02}}{\partial X_{2}}-X_{3} \frac{\partial^{2} u_{03}}{\partial X_{2}{ }^{2}}-\bar{\alpha}_{22}(T) \Delta T \\
\frac{\partial u_{01}}{\partial X_{2}}+\frac{\partial u_{02}}{\partial X_{1}}-X_{3} \frac{\partial^{2} u_{03}}{\partial X_{2}{ }^{2}}-X_{3} \frac{\partial^{2} u_{03}}{\partial X_{1}{ }^{2}}-2 \bar{\alpha}_{12}(T) \Delta T
\end{array}\right\} \\
& \left\{\begin{array}{l}
\sigma_{X_{2} X_{3}} \\
\sigma_{X_{1} X_{3}}
\end{array}\right\}^{(n)}=\left[\begin{array}{ll}
\bar{Q}_{44}(T) & \bar{Q}_{45}(T) \\
\bar{Q}_{45}(T) & \bar{Q}_{55}(T)
\end{array}\right]^{(n)}\left\{\begin{array}{l}
\frac{\partial u_{02}}{\partial X_{2}}-\frac{\partial u_{03}}{\partial X_{2}} \\
\frac{\partial u_{03}}{\partial X_{1}}-\frac{\partial u_{03}}{\partial X_{1}}
\end{array}\right\}
\end{aligned}
$$

where $\bar{Q}_{i j}(T)$ is the transformed reduced material properties which depends the temperature $(T)$ are given as follows:

$$
\begin{aligned}
& \bar{Q}_{11}(T)=Q_{11}(T) \cos ^{4} \theta+2\left(Q_{12}(T)+2 Q_{66}(T)\right) \sin ^{2} \theta \cos ^{2} \theta+Q_{22}(T) \sin ^{4} \theta \\
& \bar{Q}_{12}(T)=\left(Q_{11}(T)+Q_{22}(T)-4 Q_{66}(T)\right) \sin ^{2} \theta \cos ^{2} \theta+Q_{12}(T)\left(\sin ^{4} \theta+\cos ^{4} \theta\right) \\
& \bar{Q}_{22}(T)=Q_{11}(T) \sin ^{4} \theta+2\left(Q_{12}(T)+2 Q_{66}(T)\right) \sin ^{2} \theta \cos ^{2} \theta+Q_{22}(T) \cos ^{4} \theta \\
& \bar{Q}_{16}(T)=\left(Q_{11}(T)-Q_{12}(T)-2 Q_{66}(T)\right) \sin \theta \cos ^{3} \theta+\left(Q_{12}(T)-Q_{22}(T)+2 Q_{66}(T)\right) \sin ^{3} \theta \cos \theta \\
& \bar{Q}_{26}(T)=\left(Q_{11}(T)-Q_{12}(T)-2 Q_{66}(T)\right) \sin ^{3} \theta \cos \theta+\left(Q_{12}(T)-Q_{22}(T)+2 Q_{66}(T)\right) \sin \theta \cos ^{3} \theta
\end{aligned}
$$




$$
\begin{aligned}
\bar{Q}_{66}(T) & =\left(Q_{11}(T)+Q_{22}(T)-2 Q_{12}(T)-2 Q_{66}(T)\right) \sin ^{2} \theta \cos ^{2}+Q_{66}(T)\left(\sin ^{4} \theta+\cos ^{4} \theta\right) \\
\bar{Q}_{44}(T) & =Q_{44}(T) \cos ^{2} \theta+Q_{55}(T) \sin ^{2} \theta \\
\bar{Q}_{45}(T) & =\left(Q_{55}(T)-Q_{44}(T)\right) \cos \theta \sin \theta \\
\bar{Q}_{55}(T) & =Q_{44}(T) \sin ^{2} \theta+Q_{55}(T) \cos ^{2} \theta
\end{aligned}
$$

where, $\theta$ is the fiber orientation angle. Components of the $Q_{i j}$ are given as follows;

$$
\begin{gathered}
Q_{11}(T)=\frac{E_{1}(T)}{1-v_{12} v_{21}}, \quad Q_{22}(T)=\frac{E_{2}(T)}{1-v_{12} v_{21}} \\
Q_{12}(T)=\frac{v_{12} E_{2}(T)}{1-v_{12} v_{21}}=\frac{v_{21} E_{1}(T)}{1-v_{12} v_{21}} \quad Q_{44}^{(n)}(T)=G_{23}^{(n)}(T) \quad Q_{55}^{(n)}(T)=G_{13}^{(n)}(T) \\
Q_{21}(T)=\frac{v_{12} E_{2}(T)}{1-v_{12} v_{21}}=\frac{v_{21} E_{1}(T)}{1-v_{12} v_{21}} \quad Q_{66}(T)=G_{12}(T)
\end{gathered}
$$

The material properties of orthotropic laminated plate is a function of temperature $(T)$ as follows (Shen[67]; Li and Qiao[68]).

$$
\begin{aligned}
& E_{1}(T)=E_{1}\left(1-0,5 * 10^{-3} \Delta T\right) G P a \\
& E_{2}(T)=E_{2}\left(1-0,2 * 10^{-3} \Delta T\right) G P a \\
& G_{12}(T)=G_{13}(T)=G_{12}\left(1-0,2 * 10^{-3} \Delta T\right) G P a \\
& G_{23}(T)=G_{23}\left(1-0,2 * 10^{-3} \Delta T\right) G P a \\
& \alpha_{1}(T)=\alpha_{1}\left(1+0,5 * 10^{-3} \Delta T\right) /{ }^{\circ} \mathrm{C} \\
& \alpha_{2}(T)=\alpha_{2}\left(1+0,5 * 10^{-3} \Delta T\right) /{ }^{\circ} \mathrm{C}
\end{aligned}
$$

The transformed the thermal expansion coefficients $\alpha_{X_{1} X_{1}}, \alpha_{X_{2} X_{2}}, \alpha_{X_{1} X_{2}}$ are given as follows;

$$
\begin{aligned}
& \alpha_{X_{1} X_{1}}=\alpha_{1} \cos ^{2} \theta+\alpha_{2} \sin ^{2} \theta \\
& \alpha_{X_{2} X_{2}}=\alpha_{2} \cos ^{2} \theta+\alpha_{1} \sin ^{2} \theta \\
& 2 \alpha_{X_{1} X_{2}}=2\left(\alpha_{1}-\alpha_{2}\right) \sin \theta \cos \theta
\end{aligned}
$$

where $\alpha_{1}$ and $\alpha_{2}$ are thermal expansion coefficients in $X_{1}$ and $X_{2}$ directions, respectively. Stress resultants are given as follows;

$$
\left\{\begin{array}{l}
\{N\} \\
\{M\}
\end{array}\right\}=\left[\begin{array}{ll}
{[A(T)]} & {[B(T)]} \\
{[B(T)]} & {[D(T)}
\end{array}\right]\left\{\begin{array}{c}
\left\{\varepsilon^{0}\right\} \\
\left\{\varepsilon^{1}\right\}
\end{array}\right\}-\left\{\begin{array}{l}
\left\{N^{T}\right\} \\
\left\{M^{T}\right\}
\end{array}\right\}
$$

where $N$ is normal force and $M$ is moment. $\left\{N^{T}\right\}$ and $\left\{M^{T}\right\}$ are thermal force resultants:

$$
\begin{aligned}
& \left\{N^{T}\right\}=\sum_{n=1}^{N} \int_{Z_{n}}^{z_{n+1}} \bar{Q}_{i j}(T)^{n}\{\bar{\alpha}(T)\}^{n} \Delta T d X_{3} \\
& \left\{M^{T}\right\}=\sum_{n=1}^{N} \int_{z_{n}}^{z_{n+1}} \bar{Q}_{i j}(T)^{n}\{\bar{\alpha}(T)\}^{n} \Delta T X_{3} d X_{3}
\end{aligned}
$$

$\left\{\varepsilon^{0}\right\}$ and $\left\{\varepsilon^{1}\right\}$ are given as follows;

$$
\left\{\varepsilon^{0}\right\}=\left\{\begin{array}{c}
\frac{\partial u_{01}}{\partial X_{1}} \\
\frac{\partial u_{02}}{\partial X_{2}} \\
\frac{\partial u_{01}}{\partial X_{2}}+\frac{\partial u_{02}}{\partial X_{1}}
\end{array}\right\},\left\{\varepsilon^{1}\right\}=\left\{\begin{array}{c}
\frac{\partial \emptyset_{X_{1}}}{\partial X_{1}} \\
\frac{\partial \emptyset_{X_{2}}}{\partial X_{2}} \\
\frac{\partial \emptyset_{X_{1}}}{\partial X_{2}}+\frac{\partial \emptyset_{X_{2}}}{\partial X_{1}}
\end{array}\right\}
$$

where $A_{i j}$ is extensional stiffness, $D_{i j}$ is bending stiffness, and $B_{i j}$ is bending - extensional coupling stiffness. $A_{i j}, B_{i j}$ and $D_{i j}$ are expressed as follows: 


$$
\begin{aligned}
& \mathrm{A}_{\mathrm{ij}}=\sum_{\mathrm{k}=1}^{\mathrm{n}} \overline{\mathrm{Q}}_{\mathrm{ij}}^{(\mathrm{n})}\left(\mathrm{z}_{\mathrm{n}+1}-\mathrm{z}_{\mathrm{n}}\right) \\
& \mathrm{B}_{\mathrm{ij}}=\frac{1}{2} \sum_{\mathrm{k}=1}^{\mathrm{n}} \overline{\mathrm{Q}}_{\mathrm{ij}}^{(\mathrm{n})}\left(\mathrm{z}_{\mathrm{n}+1}^{2}-\mathrm{z}_{\mathrm{n}}^{2}\right) \\
& \mathrm{D}_{\mathrm{ij}}=\frac{1}{3} \sum_{\mathrm{k}=1}^{\mathrm{n}} \overline{\mathrm{Q}}_{\mathrm{ij}}^{(\mathrm{n})}\left(\mathrm{z}_{\mathrm{n}+1}^{3}-\mathrm{z}_{\mathrm{n}}^{3}\right)
\end{aligned}
$$

The elastic strain energy $\left(U_{i}\right)$ and the kinetic energy $(T)$ of laminated plate are expressed as follows:

$$
\begin{aligned}
& U_{i}=\frac{1}{2} \int_{V} \sigma_{i j} \varepsilon_{i j} d V \\
& T=\frac{1}{2} \int_{V} \rho\left[\left(\frac{\partial u_{01}}{\partial t}\right)^{2}+\left(\frac{\partial u_{02}}{\partial t}\right)^{2}+\left(\frac{\partial u_{03}}{\partial t}\right)^{2}\right] d V
\end{aligned}
$$

The Hamilton's principle of the problem is as follows;

$$
\delta \int_{0}^{t}\left[T-U_{i}\right] d t
$$

After using Hamilton's principle, governing equations of the laminated plate can be obtained;

$$
\begin{gathered}
\frac{\partial N_{X_{1} X_{1}}}{\partial X_{1}}+\frac{\partial N_{X_{1} X_{2}}}{\partial X_{2}}=I_{0} \frac{\partial^{2} u_{01}}{\partial t^{2}}+I_{1} \frac{\partial^{2} \emptyset_{X_{1}}}{\partial t^{2}} \\
\frac{\partial N_{X_{1} X_{2}}}{\partial X_{1}}+\frac{\partial N_{X_{2} X_{2}}}{\partial X_{2}}=I_{0} \frac{\partial^{2} u_{02}}{\partial t^{2}}+I_{1} \frac{\partial^{2} \emptyset_{X_{2}}}{\partial t^{2}} \\
\frac{\partial Q_{X_{1}}}{\partial X_{1}}+\frac{\partial Q_{X_{2}}}{\partial X_{2}}=I_{0} \frac{\partial^{2} u_{03}}{\partial t^{2}} \\
\frac{\partial M_{X_{1} X_{1}}}{\partial X_{1}}+\frac{\partial M_{X_{1} X_{2}}}{\partial X_{2}}-Q_{X_{1}}=I_{2} \frac{\partial^{2} \emptyset_{X_{1}}}{\partial t^{2}}+I_{1} \frac{\partial^{2} u_{01}}{\partial t^{2}} \\
\frac{\partial M_{X_{1} X_{2}}}{\partial X_{1}}+\frac{\partial M_{X_{2} X_{2}}}{\partial X_{2}}-Q_{X_{2}}=I_{2} \frac{\partial^{2} \emptyset_{X_{2}}}{\partial t^{2}}+I_{1} \frac{\partial^{2} u_{02}}{\partial t^{2}}
\end{gathered}
$$

where

$$
\begin{gathered}
\left\{\begin{array}{l}
N_{X_{1} X_{1}} \\
N_{X_{2} X_{2}} \\
N_{X_{1} X_{2}}
\end{array}\right\}=\int_{-\frac{h}{2}}^{\frac{h}{2}}\left\{\begin{array}{l}
\sigma_{X_{1} X_{1}} \\
\sigma_{X_{2} X_{2}} \\
\sigma_{X_{1} X_{2}}
\end{array}\right\} d X_{3} \\
\left\{\begin{array}{l}
M_{X_{1} X_{1}} \\
M_{X_{2} X_{2}} \\
M_{X_{1} X_{2}}
\end{array}\right\}=\int_{-\frac{h}{2}}^{\frac{h}{2}}\left\{\begin{array}{l}
\sigma_{X_{1} X_{1}} \\
\sigma_{X_{2} X_{2}} \\
\sigma_{X_{1} X_{2}}
\end{array}\right\} X_{3} d X_{3} \\
\left\{\begin{array}{l}
Q_{X_{2}} \\
Q_{X_{1}}
\end{array}\right\}=K\left[\begin{array}{ll}
A_{44}(T) & A_{45}(T) \\
A_{45}(T) & A_{55}(T)
\end{array}\right]\left[\begin{array}{l}
\frac{\partial u_{03}}{\partial X_{2}}+\emptyset_{X_{2}} \\
\frac{\partial u_{03}}{\partial X_{1}}+\emptyset_{X_{1}}
\end{array}\right] \\
\left\{\begin{array}{l}
I_{0} \\
I_{1} \\
I_{2}
\end{array}\right\}=\int_{-\frac{h}{2}}^{\frac{h}{2}}\left\{\begin{array}{c}
1 \\
X_{3} \\
X_{3}{ }^{2}
\end{array}\right\} \rho_{0} d X_{3}
\end{gathered}
$$

In solution of problem, Navier method is implemented in the solution of the problem. In Navier solution, boundary conditions and displacement fields the plate are given the following equations:

$u_{01}\left(X_{1}, 0, t\right)=0, \quad u_{01}\left(X_{1}, b, t\right)=0, \quad u_{02}\left(0, X_{2}, t\right)=0, \quad u_{02}\left(a, X_{2}, t\right)=0$, 


$$
\begin{aligned}
& u_{03}\left(X_{1}, 0, t\right)=0, \quad u_{03}\left(X_{1}, b, t\right)=0, \quad u_{03}\left(0, X_{2}, t\right)=0, \quad u_{03}\left(a, X_{2}, t\right)=0 \\
& \emptyset_{X_{1}}\left(X_{1}, 0, t\right)=0, \quad \emptyset_{X_{1}}\left(X_{1}, b, t\right)=0, \quad \emptyset_{X_{2}}\left(0, X_{2}, t\right)=0, \quad \emptyset_{X_{2}}\left(a, X_{2}, t\right)=0 \\
& N_{X_{1} X_{1}}^{T}\left(0, X_{2}, t\right)=0, \quad N_{X_{1} X_{1}}^{T}\left(a, X_{2}, t\right)=0, \quad N_{X_{2} X_{2}}^{T}\left(X_{1}, 0, t\right)=0, \quad N_{X_{2} X_{2}}^{T}\left(X_{1}, b, t\right)=0 \\
& M_{X_{1} X_{1}}^{T}\left(0, X_{2}, t\right)=0, \quad M_{X_{1} X_{1}}^{T}\left(a, X_{2}, t\right)=0, \quad M_{X_{2} X_{2}}^{T}\left(X_{1}, 0, t\right)=0, \quad M_{X_{2} X_{2}}^{T}\left(X_{1}, b, t\right)=0 \\
& \\
& u_{01}\left(X_{1}, X_{2}, t\right)=\sum_{n=1}^{\infty} \sum_{m=1}^{\infty} U_{1 m n}(t) \operatorname{cosk} X_{1} \operatorname{sinl} X_{2} e^{-i \beta t} \\
& u_{02}\left(X_{1}, X_{2}, t\right)=\sum_{n=1}^{\infty} \sum_{m=1}^{\infty} U_{2 m n}(t) \operatorname{sink} X_{1} \operatorname{cosl} X_{2} e^{-i \beta t} \\
& u_{03}\left(X_{1}, X_{2}, t\right)=\sum_{n=1}^{\infty} \sum_{m=1}^{\infty} U_{3 m n}(t) \operatorname{sink} X_{1} \operatorname{sinl} X_{2} e^{-i \beta t} \\
& \emptyset_{X_{1}}\left(X_{1}, X_{2}, t\right)=\sum_{n=1}^{\infty} \sum_{m=1}^{\infty} X_{X_{1} m n}(t) \operatorname{cosk} X_{1} \operatorname{sinl} X_{2} e^{-i \beta t} \\
& \emptyset_{X_{2}}\left(X_{1}, X_{2}, t\right)=\sum_{n=1}^{\infty} \sum_{m=1}^{\infty} Y_{X_{2} m n}(t) \operatorname{sink} X_{1} \operatorname{cosl} X_{2} e^{-i \beta t}
\end{aligned}
$$

where $U_{1_{m n}}, U_{2 m n}, U_{3_{m n}}, X_{X_{1 m n}}, Y_{X_{2} m}$ are displacement coefficients, $k=m \pi / L_{X_{1}}, l=$ $n \pi / L_{X_{2}}, \beta$ is the natural frequency and $i=\sqrt{-1}$. The temperature rising is defined as follows in the Navier solution;

$$
\begin{aligned}
& \Delta T\left(X_{1}, X_{2}, X_{3}, t\right)=\sum_{n=1}^{\infty} \sum_{m=1}^{\infty} T_{m n}\left(X_{3}, t\right) \operatorname{sink} X_{1} \operatorname{sinl} X_{2} \\
& T_{m n}\left(X_{3}, t\right)=\frac{4}{L_{X} L_{Y}} \int_{0}^{a} \int_{0}^{b} \Delta S\left(X_{1}, X_{2}, X_{3}, t\right) \operatorname{sink} X_{1} \operatorname{sinl} X_{2} d X_{1} d X_{2}
\end{aligned}
$$

Substituting Eqs. (17-19) into Eqs. (15), and then using matrix procedure, the algebraic equations of free vibration problem can be expressed as follows;

where

$$
\left(\left[\begin{array}{ccccc}
p_{11} & p_{12} & 0 & p_{14} & p_{15} \\
p_{12} & p_{22} & 0 & p_{24} & p_{25} \\
0 & 0 & p_{33} & p_{34} & p_{35} \\
p_{14} & p_{24} & p_{34} & p_{44} & p_{45} \\
p_{15} & p_{25} & p_{35} & p_{45} & p_{55}
\end{array}\right]-\omega^{2}\left[\begin{array}{ccccc}
m_{11} & 0 & 0 & 0 & 0 \\
0 & m_{22} & 0 & 0 & 0 \\
0 & 0 & m_{33} & 0 & 0 \\
0 & 0 & 0 & m_{44} & 0 \\
0 & 0 & 0 & 0 & m_{55}
\end{array}\right]\right)\left\{\begin{array}{c}
U_{1 m n} \\
U_{2 m n} \\
U_{3 m n} \\
X_{X_{1}} \\
Y_{X_{2}}
\end{array}\right\}=\left\{\begin{array}{l}
0 \\
0 \\
0 \\
0 \\
0
\end{array}\right\}(20)
$$

$$
\begin{aligned}
& p_{11}=\left(A_{11}(T) k^{2}+A_{66}(T) l^{2}\right), p_{12}=\left(A_{12}(T)+A_{66}(T)\right) k l \\
& p_{14}=\left(B_{11}(T) k^{2}-B_{66}(T) l^{2}\right), p_{15}=\left(B_{12}(T)+B_{66}(T)\right) k l, \\
& p_{22}=\left(A_{66}(T) k^{2}+A_{22}(T) l^{2}\right), p_{24}=p_{15} \\
& p_{25}=\left(B_{66}(T) k^{2}+B_{22}(T) l^{2}\right), p_{33}=K\left(A_{55}(T) k^{2}+A_{44}(T) l^{2}\right), \\
& p_{34}=K A_{55}(T) k, p_{35}=K A_{44}(T) l \\
& p_{44}=\left(D_{11}(T) k^{2}+D_{22}(T) l^{2}+K A_{55}(T)\right) \\
& p_{45}=\left(D_{12}(T)+D_{66}(T)\right) k l, p_{55}=\left(D_{66}(T) k^{2}+D_{22}(T) l^{2}+K A_{44}(T)\right) k \\
& m_{11}=I_{0}, m_{22}=I_{0}, m_{33}=I_{0}, m_{44}=I_{2}, m_{55}=I_{2}
\end{aligned}
$$

where $K$ is shear correction factor. Dimensionless fundamental frequency $\bar{\omega}$ is defined as follows;

$$
\bar{\omega}_{m n}=\omega_{m n}\left(L_{X_{2}}^{2} / \pi^{2}\right) \sqrt{\rho h / D_{22}}
$$




\section{Numerical Results}

In numerical study, dimensionless frequencies of cross-ply laminated simply-supported plate are calculated obtained in figures for different temperature values, orientation angles and sequence of laminas in temperature-dependent physically property. The mechanical properties of manufactured using graphite epoxy and its material parameters are; $E_{l}=150 \mathrm{GPa}, E_{2}=9 \mathrm{GPa}$, $E_{3}=9 \mathrm{GPa}, G_{12}=7,1 \mathrm{GPa}, G_{23}=2,5 \mathrm{GPa}, G_{13}=7,1 \mathrm{GPa}, \rho=1600 \mathrm{~kg} / \mathrm{m}^{3}, v_{12}=v_{21}=0.3, \alpha_{1}=$ $1,1.10^{-6}, \alpha_{1}=25,2.10^{-6}$ at $30^{\circ} \mathrm{C}$ ( $\mathrm{Li}$ and Qiao [68], Oh vd. [69]). The dimensions of plate are considered as follows: $L_{X_{1}}=4 \mathrm{~m}, L_{X_{2}}=4 \mathrm{~m}, h=0.2 \mathrm{~m}$. In the obtaining the numerical results and figures, MATLAB program is used. It is noted that temperature rising of bottom surface $\Delta T_{B}$ is changed and the temperature of the top surface $\Delta T_{T}$ is constant $\Delta T_{T}=20^{\circ} \mathrm{C}$ in the numerical calculations.

In the numerical results, the relation between temperature rising and dimensionless natural frequencies is presented for different orientation angles and sequence of laminas. Also the difference between temperature dependent and independent physical properties on the dimensionless natural frequencies of laminated composite plate is discussed. For this purpose, figures 2,3,4 and 5 show the effect of the temperature rising on the first three lower dimensionless natural frequencies of the laminated plate for 0/0, 0/90, 90/0 and 90/90, respectively in two layer sequence in both temperature dependent and independent physical properties. Also, figures 6,7,8,9 and 10 show effect of temperature rising on first three lower dimensionless natural frequencies of the laminated plate for 0/0/0, 0/90/0, 90/0/90, 0/90/90 and $90 / 90 / 90$, respectively in three layer sequence in both temperature dependent and independent physical properties.

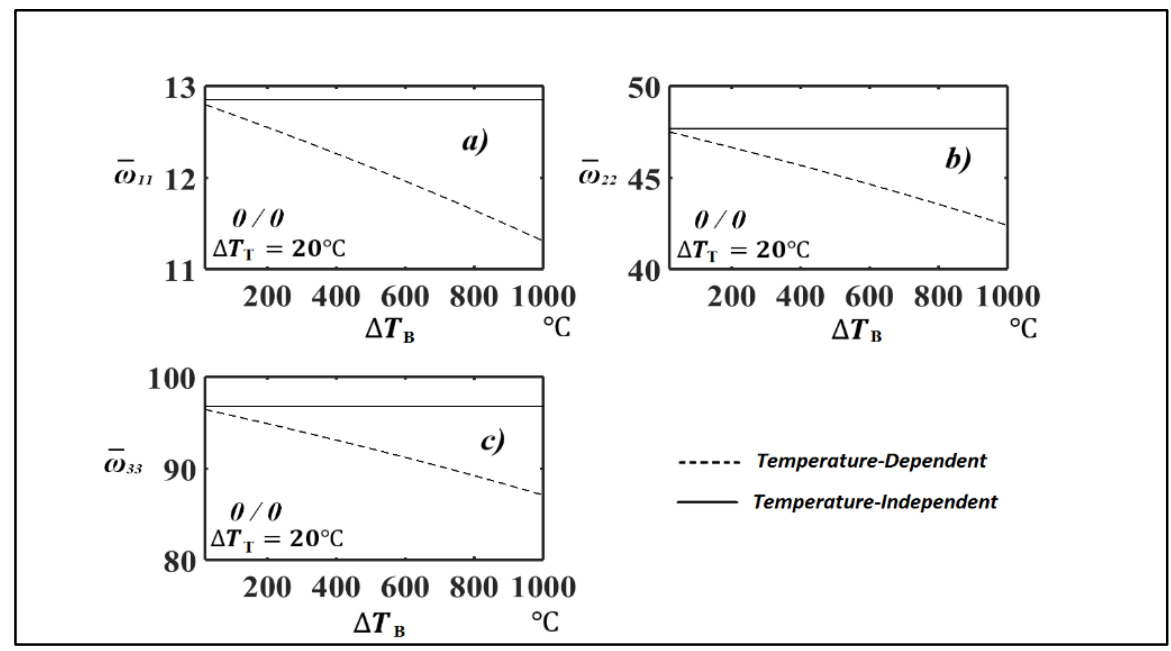

Fig. 2. The natural frequencies versus temperature rising for the two layers for stacking sequence $0 / 0$ for a) $\bar{\omega}_{11}$ b) $\bar{\omega}_{22}$ and c) $\bar{\omega}_{33}$. 


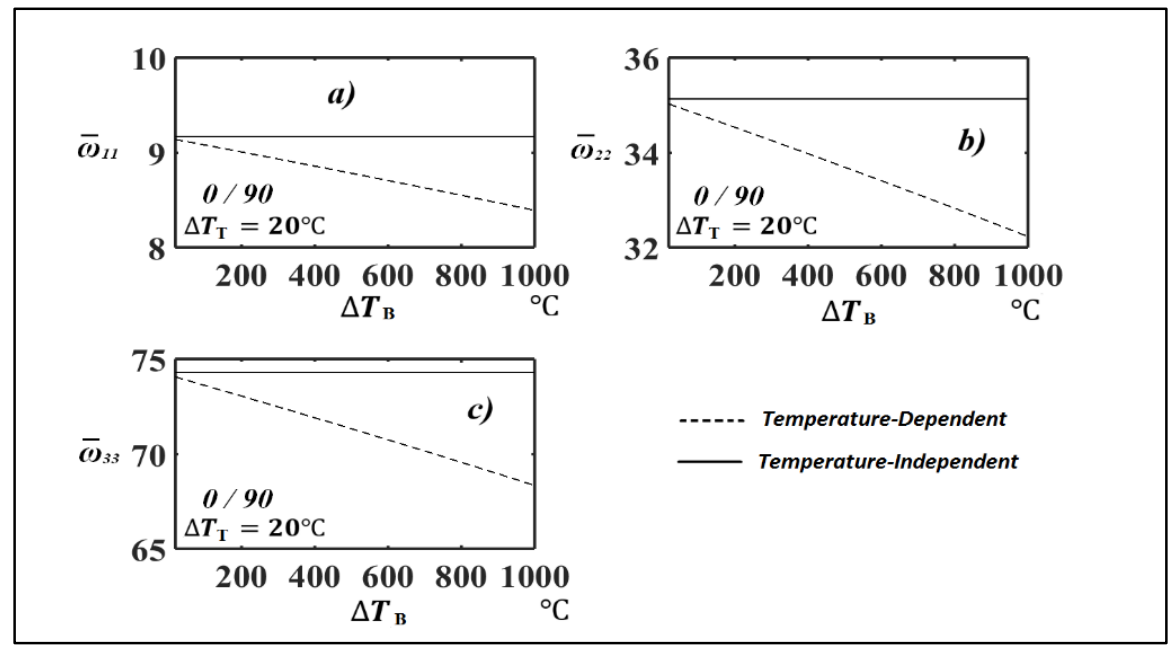

Fig. 3. The natural frequencies versus temperature rising for the two layers for stacking sequence $0 / 90$ for a) $\bar{\omega}_{11}$ b) $\bar{\omega}_{22}$ and c) $\bar{\omega}_{33}$.

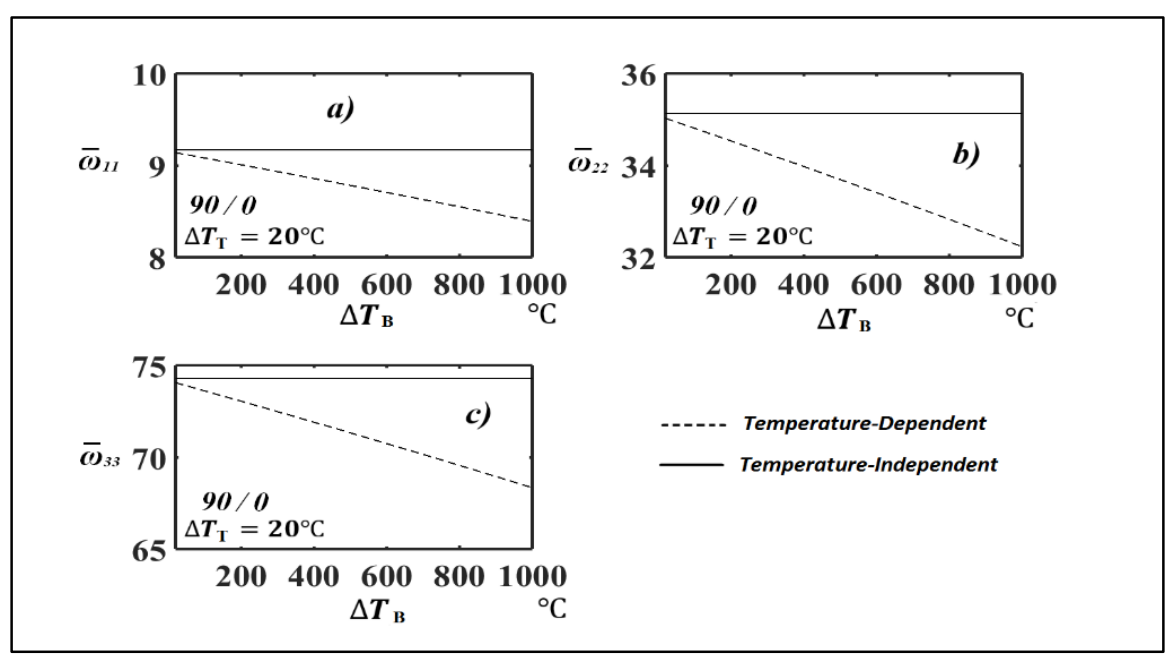

Fig. 4. The natural frequencies versus temperature rising for the two layers for stacking sequence $90 / 0$ for a) $\bar{\omega}_{11}$ b) $\bar{\omega}_{22}$ and c) $\bar{\omega}_{33}$.

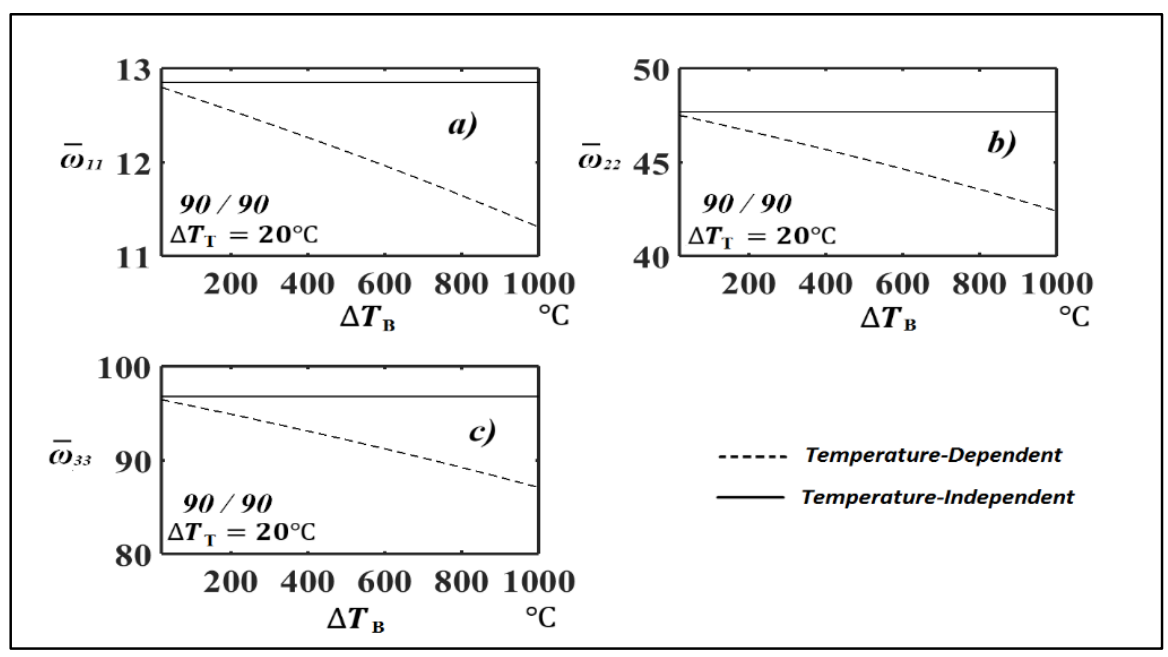

Fig. 5. The natural frequencies versus temperature rising for the two layers for stacking sequence 90/90 for a) $\bar{\omega}_{11}$ b) $\bar{\omega}_{22}$ and c) $\bar{\omega}_{33}$. 


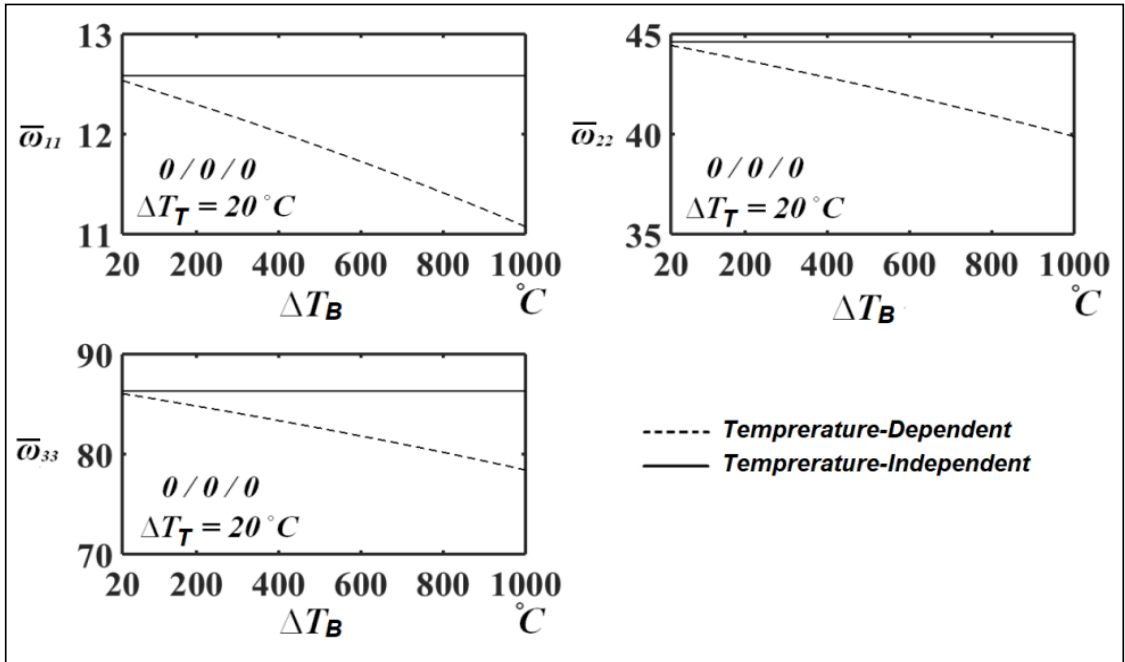

Fig. 6. The natural frequencies versus temperature rising for the three layers for stacking sequence $0 / 0 / 0$ for a) $\bar{\omega}_{11}$ b) $\bar{\omega}_{22}$ and c) $\bar{\omega}_{33}$.

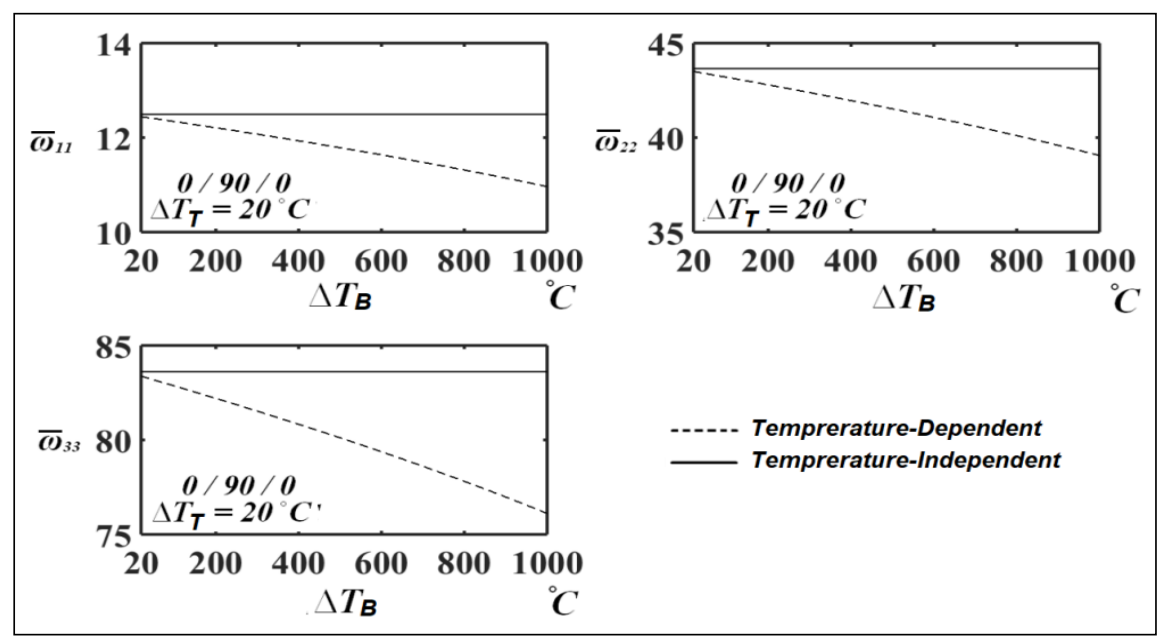

Fig. 7. The natural frequencies versus temperature rising for the three layers for stacking sequence $0 / 90 / 0$ for a) $\bar{\omega}_{11}$ b) $\bar{\omega}_{22}$ and c) $\bar{\omega}_{33}$.

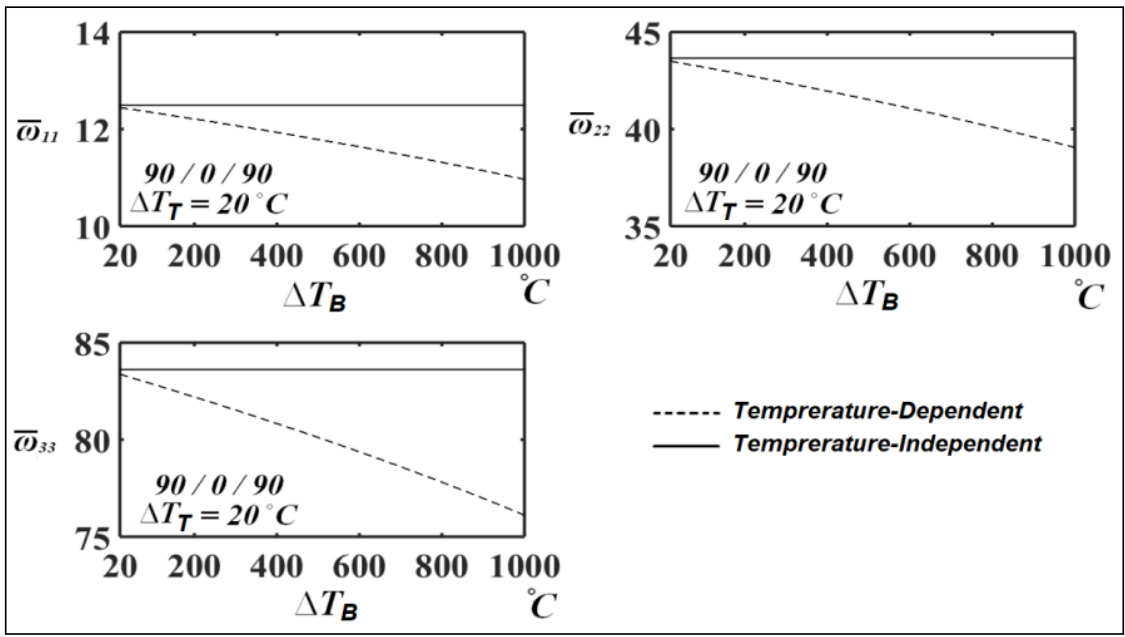

Fig. 8. The natural frequencies versus temperature rising for the three layers for stacking sequence $90 / 0 / 90$ for a) $\bar{\omega}_{11}$ b) $\bar{\omega}_{22}$ and c) $\bar{\omega}_{33}$. 


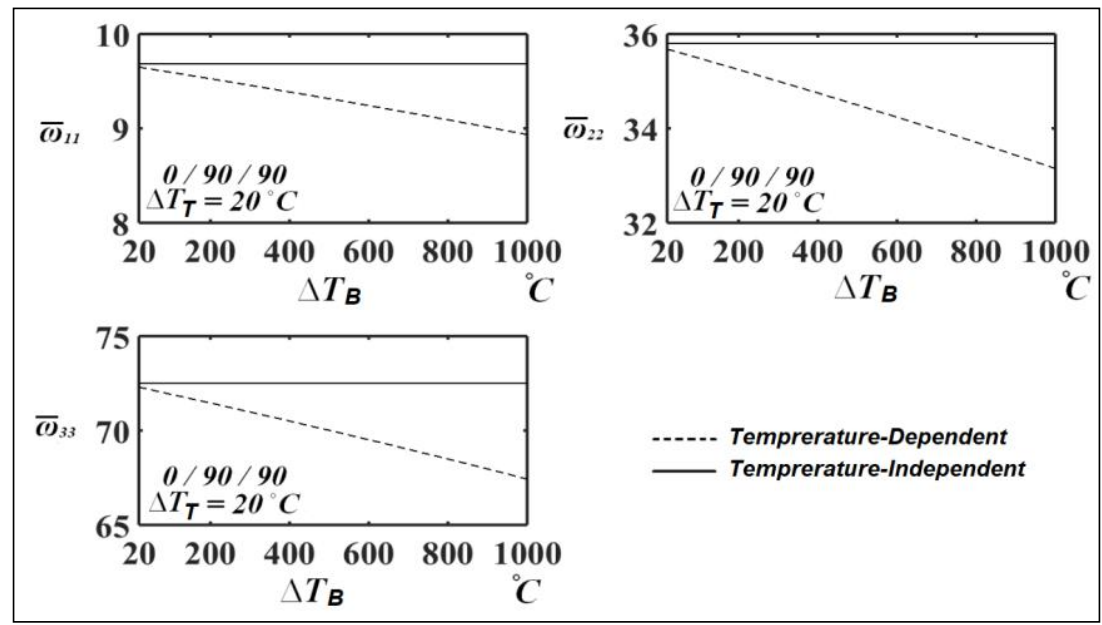

Fig. 9. The natural frequencies versus temperature rising for the three layers for stacking sequence $0 / 90 / 90$ for a) $\bar{\omega}_{11}$ b) $\bar{\omega}_{22}$ and c) $\bar{\omega}_{33}$.

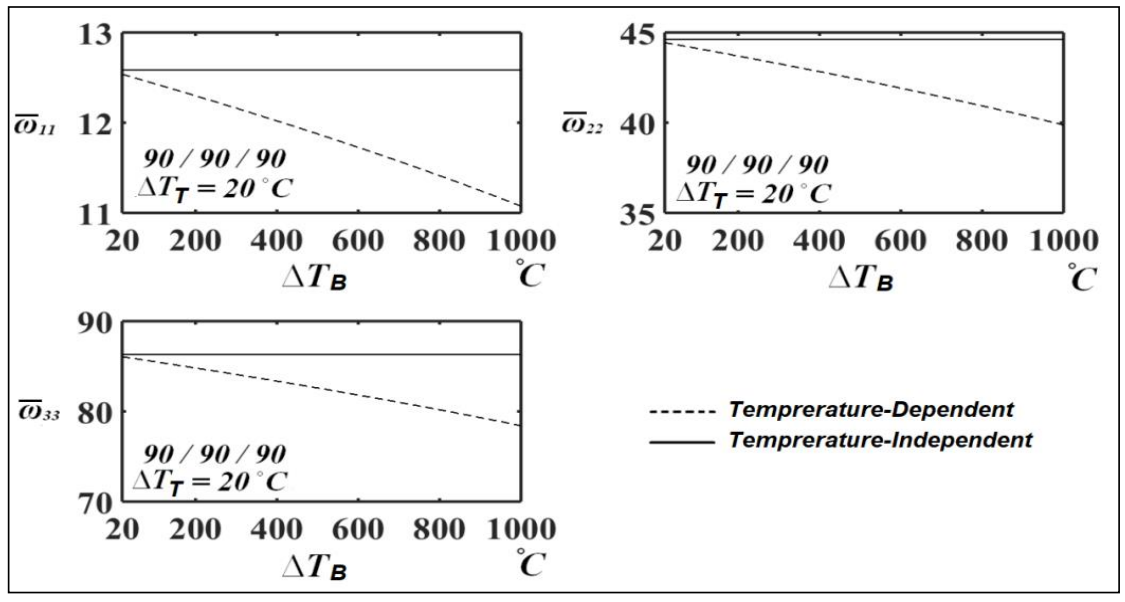

Fig. 10. The natural frequencies versus temperature rising for the three layers for stacking sequence 90/90/90 for a) $\bar{\omega}_{11}$ b) $\bar{\omega}_{22}$ and c) $\bar{\omega}_{33}$.

Figures 2-10 display that increasing in temperature, dimensionless frequency of laminated plate decreases significantly. With increasing temperature, the results of difference between temperature dependent and independent properties increase considerably.

Frequencies of temperature dependent are smaller than the frequencies of temperature independent. This is because; with the temperature increase, the strength of laminated plate decreases in the temperature dependent physical properties, so the frequencies decrease naturally. However, the strength of the laminated plate does not change with temperature increase in the temperature independent physical properties.

With changing the orientation angles, the dimensionless frequency change significantly. With increasing the orientation angles from 0 degree, the dimensionless frequency decrease considerably. Also, the stacking sequence play important role on vibration characterises of the laminated composite plate. In is observed from these figures that stacking sequence is very effective on thermal vibration responses. 


\section{Conclusions}

In the presented paper, free vibration of a laminated plate is studied under thermal loading by using FSDPT in temperature-dependent physically properties. Cross-ply laminated sequence and simply-supported boundary conditions are considered. The Navier solution is implemented in the solution method. Effects of temperature, sequence of laminas and orientation angle of layers on the vibration characterises of laminated plate are investigated in temperature dependent physical properties. Also, difference between temperature dependent and independent are examined on the vibration results. As seen from the graphs that increasing temperature yields to increasing difference between the temperature dependent and independent results. Increasing fiber orientation angles and temperature yields to decreasing the frequency values. Frequencies of temperature dependent physical properties are smaller than those of temperature independent's. Stacking sequence and orientation angle of layers play important role on vibration behavior of composite laminated plates.

\section{Acknowledgments}

This work has been supported by Research Fund of the Bursa Technical University. Project Number: 172L22.

\section{References}

[1] Pal, M. C., Large amplitude free vibration of circular plates subjected to aerodynamic heating. International Journal of Solids and Structures, 6(3), 301-313, 1970.

[2] Chen, L.W., Chen, L.Y., Thermal buckling behavior of laminated composite plates with temperaturedependent properties. Composite Structures, 13(4), 275-287, 1989.

[3] Chen, L.W., Chen, L.Y., Thermal postbuckling behaviors of laminated composite plates with temperature-dependent properties. Composite Structures, 19(3), 267-283, 1991.

[4] Liu, C.F., Huang, C.H., Free vibration of composite laminated plates subjected to temperature changes. Computers \& Structures, 60(1), 95-101, 1996.

[5] Lee, J.M., Chung, J.H., Chung, T.Y., Free vibration analysis of symmetrically laminated composite rectangular plates. Journal of Sound and Vibration, 199(1), 71-85 1997.

[6] Reddy, J.N., Chin, C.D., Thermomechanical analysis of functionally graded cylinders and plates. Journal of Thermal Stresses, 21(6), 593-626, 1998.

[7] Lee, H.J., Saravanos, D.A., The effect of temperature dependent material properties on the response of piezoelectric composite materials. Journal of Intelligent Material Systems and Structures, 9(7), 503-508, 1998.

[8] Reddy, J.N., Analysis of functionally graded plates. International Journal for Numerical Methods in Engineering, 47(1-3), 663-684, 2000.

[9] Jane, K.C., Hong, C.C., Thermal bending analysis of laminated orthotropic plates by the generalized differential quadrature method. Mechanics Research Communications, 27(2), 157-164, 2000.

[10] Shen, H.S., Thermal postbuckling behavior of imperfect shear deformable laminated plates with temperature-dependent properties. Computer Methods in Applied Mechanics and Engineering, 190(40-41), 5377-5390, 2001.

[11] Singha, M.K., Ramachandra, L.S., Bandyopadhyay, J.N., Thermal postbuckling analysis of laminated composite plates. Composite Structures, 54(4), 453-458, 2001.

[12] Sayman, O., Elastic-plastic and residual stresses in symmetric aluminum metal-matrix laminated plates under a linear thermal loading. Journal of Thermal Stresses, 26(4), 391-406, 2003.

[13] Patel, B.P., Lele, A.V., Ganapathi, M., Gupta, S.S., Sambandam, C.T., Thermo-flexural analysis of thick laminates of bimodulus composite materials. Composite Structures, 63(1), 11-20, 2004. 
[14] Shukla, K.K., Huang, J.H., Nath, Y., Thermal postbuckling of laminated composite plates with temperature dependent properties. Journal of Engineering Mechanics, 130(7), 818-825, 2004.

[15] Liew, K.M., Yang, J., Kitipornchai, S., Thermal post-buckling of laminated plates comprising functionally graded materials with temperature-dependent properties. Journal of Applied Mechanics, 71(6), 839-850, 2004.

[16] Emery, T.R., Dulieu-Barton, J.M., Earl, J.S., Cunningham, P.R. A generalised approach to the calibration of orthotropic materials for thermoelastic stress analysis. Composites Science and Technology, 68(3-4), 743-752, 2008.

[17] Shen, H.S., Nonlinear bending of functionally graded carbon nanotube-reinforced composite plates in thermal environments. Composite Structures, 91(1), 9-19, 2009.

[18] Zenkour, A.M., Alghamdi, N.A., Bending analysis of functionally graded sandwich plates under the effect of mechanical and thermal loads. Mechanics of Advanced Materials and Structures, 17(6), 419-432, 2010.

[19] Vosoughi, A.R., Malekzadeh, P., Banan, M.R., Thermal postbuckling of laminated composite skew plates with temperature-dependent properties. Thin-Walled Structures, 49(7), 913-922, 2011.

[20] Kishore, M.H., Singh, B.N., Pandit, M.K., Nonlinear static analysis of smart laminated composite plate. Aerospace Science and Technology, 15(3), 224-235, 2011.

[21] Sahoo, R., Singh, B.N., A new inverse hyperbolic zigzag theory for the static analysis of laminated composite and sandwich plates. Composite structures, 105, 385-397, 2013.

[22] Carrera, E., Cinefra, M., Fazzolari, F.A., Some results on thermal stress of layered plates and shells by using unified formulation. Journal of Thermal Stresses, 36(6), 589-625, 2013.

[23] Sahoo, R., Singh, B.N., A new shear deformation theory for the static analysis of laminated composite and sandwich plates. International Journal of Mechanical Sciences, 75, 324-336, 2013.

[24] Chen, C.S., Chen, C.W., Chen, W.R., Chang, Y.C., Thermally induced vibration and stability of laminated composite plates with temperature-dependent properties. Meccanica, 48(9), 2311-2323, 2013.

[25] Torabizadeh, M.A., Fereidoon, A., Navier-type bending analysis of general composite laminates under different types of thermomechanical loading. Mechanics, 19(4), 380-389, 2013.

[26] Houmat, A., Nonlinear free vibration of laminated composite rectangular plates with curvilinear fibers. Composite Structures, 106, 211-224, 2013.

[27] Khorshid, K., Farhadi, S., Free vibration analysis of a laminated composite rectangular plate in contact with a bounded fluid. Composite structures, 104, 176-186, 2013.

[28] Akbaş, Ş.D., Free vibration characteristics of edge cracked functionally graded beams by using finite element method. International Journal of Engineering Trends and Technology, 4(10), 45904597, 2013.

[29] Akbaş, Ş.D., Free vibration and bending of functionally graded beams resting on elastic foundation. Research on Engineering Structures and Materials, 1(1), 2015.

[30] Akbaş, Ş.D., Free vibration of axially functionally graded beams in thermal environment. International Journal Of Engineering \& Applied Sciences, 6(3), 37-51, 2014.

[31] Akbaş, Ş.D., Free vibration of edge cracked functionally graded microscale beams based on the modified couple stress theory. International Journal of Structural Stability and Dynamics, 17(03), $1750033,2017$.

[32] Akbaş, Ş.D., Geometrically nonlinear static analysis of edge cracked Timoshenko beams composed of functionally graded material. Mathematical Problems in Engineering, 2013.

[33] Akbaş, Ş.D., On post-buckling behavior of edge cracked functionally graded beams under axial loads. International Journal of Structural Stability and Dynamics, 15(04), 1450065, 2015.

[34] Akbaş, Ş.D. Free Vibration Analysis of Edge Cracked Functionally Graded Beams Resting on Winkler-Pasternak Foundation. International Journal of Engineering \& Applied Sciences, 7(3), 1$15,2015$.

[35] Akbaş, Ş.D., Thermal effects on the vibration of functionally graded deep beams with porosity. International Journal of Applied Mechanics, 9(05), 1750076, 2017.

[36] Akbaş, Ş.D., Forced vibration analysis of functionally graded porous deep beams. Composite Structures, 186, 293-302, 2018.

[37] Akbaş, Ş.D., Wave propagation of a functionally graded beam in thermal environments. Steel and Composite Structures, 19(6), 1421-1447, 2015. 
[38] Akbaş, Ş.D., Forced vibration analysis of cracked functionally graded microbeams. Advances in Nano Research, 6(1), 39-55, 2018.

[39] Sayyad, A.S., Shinde, B.M., Ghugal, Y.M., Thermoelastic bending analysis of laminated composite plates according to various shear deformation theories. Open Engineering (formerly Central European Journal of Engineering), 5(1), 18-30, 2015.

[40] Sayyad, A.S., Ghugal, Y.M., Mhaske, B. A. A four-variable plate theory for thermoelastic bending analysis of laminated composite plates. Journal of Thermal Stresses, 38(8), 904-925, 2015.

[41] Li, Z.M., Qiao, P., Thermal postbuckling analysis of anisotropic laminated beams with different boundary conditions resting on two-parameter elastic foundations. European Journal of Mechanics-A/Solids, 54, 30-43, 2015.

[42] Li, Z.M., Qiao, P., Buckling and postbuckling behavior of shear deformable anisotropic laminated beams with initial geometric imperfections subjected to axial compression. Engineering Structures, 85, 277-292, 2015.

[43] Akbaş, Ş.D. Static analysis of a nano plate by using generalized differential quadrature method. International Journal Of Engineering \& Applied Sciences, 8(2), 30-39, 2016.

[44] Ramos, I.A., Mantari, J. L., Zenkour, A.M., Laminated composite plates subject to thermal load using trigonometrical theory based on Carrera Unified Formulation. Composite Structures, 143, 324-335, 2016.

[45] Akbaş, Ş.D. Stability of a non-homogenous porous plate by using generalized differantial quadrature method. International Journal of Engineering and Applied Sciences, 9, 147-155, 2017.

[46] Akbaş, Ş.D. Vibration and static analysis of functionally graded porous plates. Journal of Applied and Computational Mechanics, 3(3), 199-207, 2017.

[47] Choudhury, A., Mondal, S.C., Sarkar, S. Effect of lamination angle and thickness on analysis of composite plate under thermo mechanical loading. Strojnicky casopis-Journal of Mechanical Engineering, 67(1), 5-22, 2017.

[48] Akbaş, Ş.D. Large deflection analysis of a fiber reinforced composite beam. Steel and Composite Structures, An International Journal ,27(5), 567-576, 2018.

[49] Akbaş, Ş.D. Post-buckling responses of a laminated composite beam. Steel and Composite Structures, 26(6), 733-743, 2018.

[50] Akbaş, Ş.D. İki Malzemeli Kompozit Bir Kirişin Serbest ve Zorlanmış Titreşimlerinin İncelenmesi. Politeknik Dergisi, 21(1), 65-73,2018.

[51] Akbaş, Ş.D. Geometrically nonlinear analysis of a laminated composite beam. Structural Engineering and Mechanics, An International Journal , 66(1), 27-36, 2018.

[52] Yüksel, Y.Z., Akbaş, Ş.D., Kara, İ.F., Sıcaklık Etkisi Altındaki Bir Plağın Serbest Titreşim Analizi. 20. Ulusal Mekanik Kongresi, Bursa, Turkey, 2017.

[53] Yüksel, Y.Z., and Akbaş, Ş.D., Stress Analysis of a Laminated Composite Plate Under Temperature Rising. 7th International Conference on Advanced Technologies, Antalya, Turkey, 2018.

[54] Baltacioglu A.K., Akgoz, B., Civalek, O., Nonlinear static response of laminated composite plates by discrete singular convolution method. Composite Structures 93,153-161, 2010.

[55] Baltacioglu, A.K., Civalek, O., Akgoz, B., Demir, F., Large deflection analysis of laminated composite plates resting on nonlinear elastic foundations by the method of discrete singular convolution. International Journal of Pressure Vessels and Piping 88, 290-300, 2011.

[56] Baltacioglu, A.K., Akgoz, B., Civalek, O., Nonlinear static response of laminated composite plates by discrete singular convolution method. Composite Structures 93, 153-161, 2010.

[57] Civalek, O., Nonlinear dynamic response of laminated plates resting on nonlinear elastic foundations by the discrete singular convolution-differential quadrature coupled approaches. Composites: Part B, 50, 171-179, 2013.

[58] Shahba, A., Attarnejada, R., Hajilar, S., Free vibration and stability of axially functionally graded tapered Euler-Bernoulli beams. Shock and Vibration, 18,683-696, 2011.

[59] Civalek, O., Demir, C., Buckling and bending analyses of cantilever carbon nanotubes using the eulerbernoulli beam theory on non-local continuum model. Asian Journal of Civil Engineering, 12(5), 651-661, 2011.

[60] Akgöz, B, Civalek, O., Buckling analysis of cantilever carbon nanotubes using the strain gradient elasticity and modified couple stress theories. Journal of Computational and Theoretical Nanoscience, 8, 1821-1827, 2011. 
[61] Wan Ji Chen, WJ., Li, XP., Size-dependent free vibration analysis of composite laminated Timoshenko beam based on new modified couple stress theory. Arch Appl Mech, 83, 431-444, 2013.

[62] Mercan, K., Civalek, O., DSC method for buckling analysis of boron nitride nanotube (BNNT) surrounded by an elastic matrix. Composite Structures, 143, 300-309, 2016.

[63] Demir, C., Mercan, K., Civalek, O. Determination of critical buckling loads of isotropic, FGM and laminated truncated conical panel. Composites Part B, 94,1-10, 2016.

[64] Mercan, K., Civalek, O., Buckling analysis of Silicon carbide nanotubes (SiCNTs) with surface effect and nonlocal elasticity using the method of HDQ. Composites Part B, 114, 34-45, 2017.

[65] Civalek, O., Free vibration of carbon nanotubes reinforced (CNTR) and functionally graded shells and plates based on FSDT via discrete singular convolution method. Composites Part B, 111,45$59,2017$.

[66] Mercan, K., Ersoy, H. and Civalek, O., (2016). Free vibration of annular plates by discrete singular convolution and differential quadrature methods. Journal of Applied and Computational Mechanics, 2(3), 128-133, 2017.

[67] Shen, H.S., Thermal postbuckling of imperfect shear-deformable laminated plates on twoparameter elastic foundations. Mechanics of Composite Materials and Structures, 6, 207-228, 1999.

[68] Li, Z.M. and Qiao, P., Thermal postbuckling analysis of anisotropic laminated beams with different boundary conditions resting on two-parameter elastic foundations. European Journal of Mechanics-A/Solids, 54, 30-43, 2015.

[69] Oh, I.K., Han, J.H., and Lee, I., Postbuckling and vibration characteristics of piezolaminated composite plate subject to thermo-piezoelectric loads. Journal of Sound and Vibration, 233(1), 1940, 2000. 